\title{
Problematic Internet Use through Smartphones among School Adolescents in Sohag City, Egypt
}

\author{
${ }^{1}$ Taghreed A Ismail and ${ }^{2}$ Magda M Ali \\ ${ }^{1}$ Public Health and Community medicine department, Faculty of medicine, \\ Assiut University and ${ }^{2}$ Sohag University \\ Received: February, 2018 Accepted: May, 2018
}

\begin{abstract}
Background: Smartphone ownership had a significant association with problematic use of the internet and internet addiction. Objective: to determine the prevalence of problematic internet use (PIU) through smartphone among adolescents and describe the sociodemographic characteristics affecting it as well as the effect of misuse on family and peer relations. Method: An analytic cross- sectional study was carried out on 454 preparatory and secondary private school students in Sohag City, Egypt. Internet Addiction Test (IAT) was used to measure the internet use. Results: PIU was reported in $52.4 \%$ of students whereas internet addiction (IA) occurred in $4 \%$ of the students. The mean score of IAT was significantly higher among males than females $(54.7 \pm 16.9$ versus $49.9 \pm 15.4$ respectively, $\mathrm{P}=0.002)$. Social media activities were significantly higher among males $(88.0 \%)$ whereas educational internet activities were significantly higher among females $(75.2 \%)$. PIU and IA through smartphone were significantly higher among adolescents whom fathers were highly educated $(56.0 \%$ \& $5.6 \%$ respectively) and among adolescents who had internet access at home (81.9\% \& 88.9\% respectively). Bad/neutral relations with family members were significantly higher among those with PIU and IA (61.3 \& $7.5 \%$ respectively). Conclusion and recommendations: PIU through smartphones is prevalent among adolescents; males are more involved especially in social media activities. The PIU is significantly higher when internet access is available at home and among those whom fathers are highly educated. Bad family relationship is significantly higher among adolescents with PIU and IA. Interactive and media awareness programs and parents control with restriction of smartphone use among adolescents are required.
\end{abstract}

Key Words: Problematic Internet Use, Internet addiction, smartphone, Adolescents, Egypt

Corresponding auther: Taghreed Abdul-Aziz Mohammed Ismail_Email: taghrid1973@yahoo.com

\section{Introduction:}

Using modern technologies is a common feature of today's world. The Internet is one of the most widely used of these technologies, it plays an increasingly significant role in revolutionizing peoples' lives. ${ }^{1}$

Recently, it has been reported that internet based activities showed similar levels of addiction as those of drug and substance abuse. ${ }^{2}$ An increasing number of studies have focused on the most important behavioral addictions today; the Internet, videogames, and smartphones. ${ }^{3}$

The concept of internet addiction (IA) refers to the excessive use of internet which in turn causes various problems in individual, social and professional aspects. The most basic symptoms are inability to restrict internet use, to continue internet use despite social or academic hazards and feeling a deep 
anxiety when access to internet is restricted. ${ }^{4}$

In spite of numerous cons of the internet, in case of being misused, it can be risky and lead to problematic internet use (PIU) or IA which interferes with one or more main aspects of life functioning such as profession, significant relationships, school, physical health or mental health. PIU has been wellthought-out as one of the epidemics of 21 st century. ${ }^{5,6}$

The Mental health professionals suggested considering internet addiction as a mental disorder in their recent edition of Diagnostic and Statistical Manual of Mental Disorders (DSM-5, 2013). ${ }^{7}$ IA has the following symptoms: preoccupation with the internet; need to spend increasing amounts of time online; repeated but unsuccessful attempts to reduce internet use; suffering withdrawal symptoms from reduction of internet use; time management problems; environmental distress from school, family, work, and friends; deception of internet time; and mood modification through internet use. ${ }^{8}$

Adolescent IA varies widely internationally. Global prevalence rates of IA range from $1.5-8.2 \% .^{9}$ In Europe, it ranges between 1-9\%. In Asia the prevalence has been reported to be between $2 \%$ and $18 \%$ whereas in the Middle East was found to range between $1-12 \%$. Caution is required in interpretation and comparison of data from different studies as considering the scales used in assessment is crucial. ${ }^{10}$

Teenagers are likely to be the most susceptible population; they are particularly vulnerable to the initiation of addictive behaviors and they are the population subgroup most frequently using the internet, both for academic reasons or entertainment. ${ }^{11,12}$

The latest generation of mobile phones (smartphones) allows people to engage in a wide range of online activities; checking email, playing video games, or involvement in social networks without being constrained to their home. ${ }^{13}$ Smartphones are quickly replacing the lap-top or desk-top computer as the preferred method of accessing the internet. No one can now argue that it is a luxury to have ownership of a mobile phone particularly the smart ones. ${ }^{3,14}$

Considering the multi-purpose, mobile, and internet capabilities of a smartphone, it has become a prevalent social phenomenon $^{15}$ and smartphone ownership had a significant association with IA. ${ }^{16}$ Moreover, as the internet become more accessible through smartphone, the addiction pattern associated with smartphone has been shown more routinely and the concerns relating the phenomenon have increased. $^{2}$

PIU comprises an important area of research as its negative consequences have been found to impact on everyday functioning, interpersonal relationships and emotional well-being ${ }^{17}$ so there is a dead need to gain insight into the problem and develop and expand awareness about the harmful PIU. ${ }^{5}$

Availability of smartphones increases the chance of problematic use of the internet among adolescents. This study aims to determine the prevalence of problematic use of the internet through smartphones as still there is paucity of local studies in this regard.

The aim of this study is to determine the prevalence of PIU and IA through smartphones among adolescents and describe the sociodemographic characters affecting the internet use through smartphones and the effect of misuse on family and peer relations.

\section{Method:}

Study design: Analytic cross-sectional study. Study setting: private preparatory and secondary schools in Sohag city, Egypt.

Study population: primary and preparatory school students (both males 
and females) attending private schools in Sohag City. Inclusion criteria: students who have smartphones.

Private schools were chosen to increase the chance of owning personal smartphones among students.

Sample size: The sample size was calculated using EPI info program. using a prevalence rate of PIU $40.3 \%$ as reported in Saudi Arabia by Dawood et al. ${ }^{5}$ The calculated sample size was 357 at confidence level $95 \%$. A total of 454 students were interviewed.

Sampling technique: Private schools in Sohag city were stratified into male preparatory and male secondary schools, female preparatory and female secondary schools. one school was chosen randomly from each strata. School classes were used as a sample unit. $1^{\text {st }}$ and $2^{\text {nd }}$ preparatory and $1^{\text {st }}$ and $2^{\text {nd }}$ secondary school classes were included.

Data collection: A semi-structured selfadministered questionnaire was used for data collection. The questionnaire consisted of 3 parts: Part I: included sociodemographic data: age, sex, school class, parent's level of education, mother work. Part II: contains questions about: Relationship with parents, other family members and friends and daily habits as reading and practicing sports, duration and purposes of internet use. Part III: The Internet Addiction Test (IAT) scale developed by Young. ${ }^{18}$

The IAT is the most widely used questionnaire to assess PIU and IA. It is one of the most validated and widely used scales for evaluation of IA globally with many translated versions. ${ }^{5}$ The Arabic version of the IAT is a valid and reliable instrument for use in the Arab world. ${ }^{19}$

IAT consists of 20 questions investigating the degree of preoccupation, compulsive use, behavioral problems, emotional changes, and diminished functionality related to internet use as perceived by the respondent. The responses are marked on a Likert scale from 0 to 5 ( $0=$ Does not apply; $\quad 1=$ Never; $2=$ Rarely; 3=Occasionally; 4=Often; 5=Always). Item points are added to comprise a continuous total score from 0 to 100 , with higher scores indicating higher symptoms of PIU and IA. The overall score is classified to four categories: very low internet use $(\leq 19)$; normal internet use with good control and management of the time spent online (20-49); difficulties in controlling and managing the time spent online, with some consequences for the person's life (PIU) (50-79); and internet use causing significant problems in the person's life, with important consequences for emotions, relationships, and social functioning (IA) (80-100). ${ }^{17,20}$

The scale showed very good internal consistency, with an alpha coefficient of 0.93. ${ }^{19,21}$

A pilot study was carried on $5 \%$ of the sample to assess clarity of the questions, the need for any rewording and/or rephrasing and time needed to fulfill the questionnaire. Results of the pilot study were not included in the study.

The questionnaire required about 20 minutes to be completed depending on the response of the participants.

One of the researchers was available in the classroom at the time of fulfilling the questionnaire by the students to clarify any questions and to ensure completion of the questionnaire.

The field work was conducted between November, 2017 and February, 2018.

\section{Statistical analysis}

Data were entered, cleaned and recoded using the Statistical Package for Social Science (SPSS Inc., Chicago, IL, USA) version 20. Data analysis: univariate analysis; descriptive statistics (frequency $\&$ percent for qualitative data, mean \pm SD for quantitative data). Bivariate analysis: Chi-square test $(\chi 2)$ was used to test the difference between the proportions of qualitative variables. 
Student $t$ test was used to compare the mean of different groups.

Statistical significance level was considered when $\mathrm{p}<0.05$ for all statistical tests.

Ethical considerations: An official approvals for conducting the research was obtained from Sohag University, Central Agency for Public Mobilization and Statistics (CAPMAS), Issue number 771 and Ministry of education, Sohag governorate. The researchers assured voluntary participation of the students. Confidentiality of all data was assured.

Acknowledgment: The researchers would like to acknowledge school personnel who facilitated and students who participated to complete the field work of the study.

\section{Results:}

Females represented $54.2 \%$ of participating adolescents, $52.6 \%$ were 2ry school students. More than half of the students' fathers (58.6\%) and less half of the students' mothers $(47.4 \%)$ were having university education. Working mothers represented $62.3 \%$ (Table 1).

More than half of the adolescents (52.4\%) were having PIU whereas $43.6 \%$ of them were average online users. IA were reported among $4.0 \%$ of the adolescents (Fig. 1).

The highest internet uses were social media activities, educational purposes, news follow up, recreational activities and e-mail checking (fig. 2)

The mean IAT score was significantly higher among males than females $(54.7 \pm 16.9$ versus $49.9 \pm 15.4$ respectively).

Regarding internet uses through smartphones according to gender, social media activities were significantly higher among males than females ( $88.0 \%$ versus $78.0 \%$ respectively). On the other hand, educational purposes were significantly higher among females than males $(75.2 \%$ versus $64.9 \%$ respectively). Other internet activities showed no statistical
Table (1): Socio-demographic characteristics of participating adolescents

\begin{tabular}{|c|r|c|}
\hline \multicolumn{1}{|c|}{ Variable } & $\mathbf{N = 4 5 4}$ & $\mathbf{\%}$ \\
\hline Gender: & & \\
\hline Male & 208 & 45.8 \\
\hline Female & 246 & 54.2 \\
\hline Age
\end{tabular}

Age in completed years: (Mean $\pm \mathrm{SD}$ ) 15.2 $\pm 1.4$

\begin{tabular}{|l|r|r|}
\hline$\leq 15$ years & 215 & 47.4 \\
\hline$>15$ years & 239 & 52.6 \\
\hline School: & & \\
\hline Preparatory & 215 & 47.4 \\
\hline Secondary & 239 & 52.6 \\
\hline Father education: & & \\
\hline Less than 2ry education & 81 & 17.8 \\
\hline Secondary education & 107 & 23.6 \\
\hline University/ higher & 266 & 58.6 \\
\hline Mother education: & & \\
\hline Less than 2ry education & 153 & 33.7 \\
\hline Secondary education & 86 & 18.9 \\
\hline University/ higher & 215 & 47.4 \\
\hline Mother work status: & & \\
\hline Working & 283 & 62.3 \\
\hline Housewives & 171 & 37.7 \\
\hline significant differences & by gender \\
\hline
\end{tabular}

(Table 2).

PIU and IA through smartphones were significantly higher among adolescents whom fathers were highly educated $(56.0 \% \quad \& 5.6 \%$ respectively). Age, mother education and job showed no significant effect on internet use (Table $3)$.

Regarding social relations, bad/neutral relations with family members were significantly higher among adolescents who had PIU $(61.3 \%)$ and IA (7.5\%). Although adolescents with PIU / IA were having more $\mathrm{bad} /$ neutral problems with parents and friends but this difference was statistically insignificant (Table 4).

PIU and IA through smartphones were significantly higher among adolescents who had available internet access inside homes $(81.9 \%$ \& $88.9 \%$ respectively). The period of internet use showed no significant effect on the degree of internet use (Table 5).

There was no statistical significant difference regarding practicing hobbies (reading/ sports) and the degree of 
Table (2): Gender differences regarding IAT score and different internet uses among adolescents

\begin{tabular}{|c|c|c|c|c|}
\hline \multirow[b]{2}{*}{ Variable } & \multicolumn{2}{|c|}{ Gender } & \multirow[b]{2}{*}{$\begin{array}{c}\text { Statistical } \\
\text { test }\end{array}$} & \multirow[b]{2}{*}{ P-value } \\
\hline & $\begin{array}{c}\text { Males } \\
\mathrm{N}=\mathbf{2 0 8}\end{array}$ & $\begin{array}{c}\begin{array}{c}\text { Females } \\
\mathrm{N}=\mathbf{2 4 6}\end{array}\end{array}$ & & \\
\hline IAT score & $54.7 \pm 16.9$ & $49.9 \pm 15.4$ & $\mathrm{~T}=3.1$ & 0.002 \\
\hline Different Internet activities": & & & $\mathrm{X}^{2}$ & \\
\hline Social media activities & $183(88.0 \%)$ & $192(78.0 \%)$ & 7.7 & 0.005 \\
\hline Educational purposes & $135(64.9 \%)$ & $185(75.2 \%)$ & 5.8 & 0.01 \\
\hline News follow up & $132(63.5 \%)$ & $163(66.3 \%)$ & 0.4 & 0.5 \\
\hline Recreational activities & $129(62.0 \%)$ & $152(61.8 \%)$ & 0.003 & 0.9 \\
\hline Checking E-mail & $119(57.2 \%)$ & $140(56.9 \%)$ & 0.004 & 0.9 \\
\hline
\end{tabular}

\# multiple response question

Table (3): Internet use through smartphones according to socio-demographic characteristics among adolescents

\begin{tabular}{|c|c|c|c|c|c|}
\hline \multirow[b]{2}{*}{ Variable } & \multicolumn{3}{|c|}{ Internet use } & \multirow[b]{2}{*}{$\mathbf{X}^{2}$} & \multirow[b]{2}{*}{$\begin{array}{c}P- \\
\text { value }\end{array}$} \\
\hline & $\begin{array}{c}\text { Average } \\
\text { online users } \\
(\mathrm{N}=\mathbf{1 9 8})\end{array}$ & $\begin{array}{c}\text { PIU } \\
(\mathbf{N}=\mathbf{2 3 8})\end{array}$ & $\underset{(\mathrm{N}=18)}{\mathrm{IA}}$ & & \\
\hline School: & & & & \multirow{3}{*}{2.1} & \multirow{3}{*}{0.3} \\
\hline - Preparatory ( $\leq 15$ years) & $101(47.0 \%)$ & $105(48.8 \%)$ & $9(4.2 \%)$ & & \\
\hline - Secondary (>15 years) & $97(40.6 \%)$ & $133(55.6 \%)$ & $9(3.8 \%)$ & & \\
\hline \multicolumn{4}{|l|}{ Father education: } & \multirow{3}{*}{10.2} & \multirow{3}{*}{0.006} \\
\hline - Secondary/ lower & $96(51.1 \%)$ & $89(47.3 \%)$ & $3(1.6 \%)$ & & \\
\hline - University/ higher & $102(38.3 \%)$ & $149(56.0 \%)$ & $15(5.6 \%)$ & & \\
\hline \multicolumn{4}{|l|}{ Mother education: } & \multirow{3}{*}{3.6} & \multirow{3}{*}{0.2} \\
\hline - Secondary/ lower & $114(47.7 \%)$ & $117(49.0 \%)$ & $8(3.3 \%)$ & & \\
\hline - University/ higher & $84(39.1 \%)$ & $121(56.3 \%)$ & $10(4.7 \%)$ & & \\
\hline \multicolumn{4}{|l|}{ Mother work status: } & \multirow{3}{*}{1.2} & \multirow{3}{*}{0.5} \\
\hline - Working & $69(40.4 \%)$ & $95(55.6 \%)$ & $7(4.1 \%)$ & & \\
\hline - Housewives & $129(45.6 \%)$ & $143(50.5 \%)$ & $11(3.9 \%)$ & & \\
\hline
\end{tabular}

Table (4): Social relations and internet use through smartphones among adolescents

\begin{tabular}{|c|c|c|c|c|c|}
\hline \multirow[b]{2}{*}{ Variable } & \multicolumn{3}{|c|}{ Internet use } & \multirow[b]{2}{*}{$\mathbf{X}^{2}$} & \multirow[b]{2}{*}{$\begin{array}{c}P \text { - } \\
\text { value }\end{array}$} \\
\hline & $\begin{array}{l}\text { Average } \\
(\mathrm{N}=198)\end{array}$ & $\begin{array}{c}\text { Frequent } \\
\text { problems } \\
(\mathrm{N}=283)\end{array}$ & $\begin{array}{c}\text { Significant } \\
\text { problems } \\
(\mathrm{N}=18)\end{array}$ & & \\
\hline \multicolumn{4}{|l|}{ Relation with parents: } & \multirow{3}{*}{5.8} & \multirow{3}{*}{0.05} \\
\hline $\mathrm{Bad} / \mathrm{neutral}$ & $15(28.3 \%)$ & $35(66.0 \%)$ & $3(5.7 \%)$ & & \\
\hline Good & $183(45.6 \%)$ & $203(50.6 \%)$ & $15(3.7 \%)$ & & \\
\hline \multicolumn{4}{|c|}{ Relation with family members: } & \multirow{3}{*}{7.9} & \multirow{3}{*}{0.01} \\
\hline $\mathrm{Bad} /$ neutral & $25(31.3 \%)$ & $49(61.3 \%)$ & $6(7.5 \%)$ & & \\
\hline Good & $173(46.3 \%)$ & $189(50.5 \%)$ & $12(3.2 \%)$ & & \\
\hline \multicolumn{4}{|l|}{ Relation with friends: } & \multirow{3}{*}{2.1} & \multirow{3}{*}{0.3} \\
\hline $\mathrm{Bad} /$ neutral & $38(40.0 \%)$ & $51(53.7 \%)$ & $6(6.3 \%)$ & & \\
\hline Good & $160(44.6 \%)$ & $187(52.1 \%)$ & $12(3.3 \%)$ & & \\
\hline
\end{tabular}

internet use through smartphones (Table 6).

\section{Discussion:}

In the present study, more than half of the participants were having PIU, while $4.0 \%$ experienced significant problems (internet addiction) whereas $43.6 \%$ were average internet users. This is in 
Table (5): Internet use through smartphones according to place and period of internet use among adolescents

\begin{tabular}{|c|c|c|c|c|c|}
\hline \multirow[b]{2}{*}{ Variable } & \multicolumn{3}{|c|}{ Internet use } & \multirow[b]{2}{*}{$\mathrm{X} 2$} & \multirow[b]{2}{*}{$\begin{array}{c}\text { P- } \\
\text { value }\end{array}$} \\
\hline & $\begin{array}{l}\text { Average } \\
(\mathrm{N}=198)\end{array}$ & $\begin{array}{l}\text { Frequent } \\
\text { problems } \\
(\mathbf{N}=\mathbf{2 3 8})\end{array}$ & $\begin{array}{c}\text { Significant } \\
\text { problems } \\
(\mathbf{N}=18)\end{array}$ & & \\
\hline Indoor internet availability & $140(70.7 \%)$ & $195(81.9 \%)$ & $16(88.9 \%)$ & 9.2 & 0.01 \\
\hline Outdoor internet use & $121(61.1 \%)$ & $145(60.9 \%)$ & $12(66.7 \%)$ & 0.2 & 0.8 \\
\hline \multicolumn{4}{|l|}{ Period of use: } & \multirow{3}{*}{2.4} & \multirow{3}{*}{0.3} \\
\hline Less than 5 years (293) & $133(45.4 \%)$ & $151(51.5 \%)$ & $9(3.1 \%)$ & & \\
\hline 5 years and more $(161)$ & $65(40.4 \%)$ & $87(54.0 \%)$ & $9(5.6 \%)$ & & \\
\hline
\end{tabular}

Table (6): Internet use through smartphones and practices of other hobbies among adolescents

\begin{tabular}{|c|c|c|c|c|c|}
\hline \multirow[b]{2}{*}{ Variable } & \multicolumn{3}{|c|}{ Internet use } & \multirow[b]{2}{*}{$\mathbf{X} 2$} & \multirow[b]{2}{*}{$\begin{array}{c}\mathbf{P}- \\
\text { value }\end{array}$} \\
\hline & $\begin{array}{l}\text { Average } \\
(\mathrm{N}=198)\end{array}$ & $\begin{array}{c}\text { Frequent } \\
\text { problems } \\
(\mathbf{N}=\mathbf{2 3 8})\end{array}$ & $\begin{array}{c}\text { Significant } \\
\text { problems } \\
(\mathrm{N}=18)\end{array}$ & & \\
\hline Reading: & & & & \multirow{3}{*}{3.4} & \multirow{3}{*}{0.2} \\
\hline Yes & $168(45.5 \%)$ & $188(50.9 \%)$ & $13(3.5 \%)$ & & \\
\hline No & $30(35.3 \%)$ & $50(58.8 \%)$ & $5(5.9 \%)$ & & \\
\hline $\begin{array}{l}\text { Sports at least half an } \\
\text { hour/ day: }\end{array}$ & & & & \multirow{3}{*}{3.1} & \multirow{3}{*}{0.2} \\
\hline Yes & $108(40.8 \%)$ & $148(55.8 \%)$ & $9(3.4 \%)$ & & \\
\hline No & $90(47.6 \%)$ & $90(47.6 \%)$ & $9(4.8 \%)$ & & \\
\hline
\end{tabular}

concordance with other studies in Saudi Arabia and China. ${ }^{5,22}$ Whereas a lower prevalence of PIU and IA Goel et al. was reported among high school students in many other studies. ${ }^{21,23,24}$

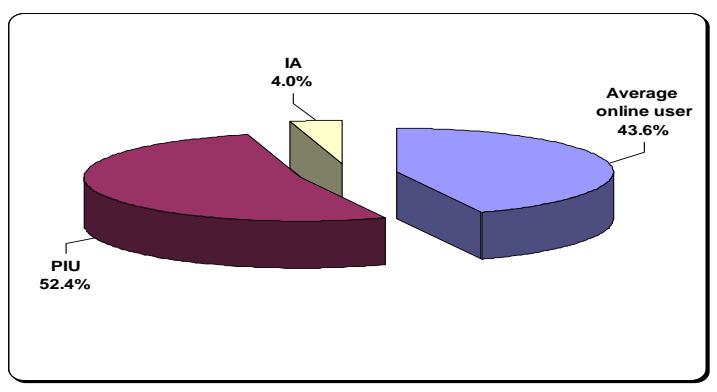

Fig. (1): Classification of the internet use among adolescents

N.B IAT score $52.1 \pm 16.3(20-90)$

On the other hand, a much higher prevalence rate $(15.1 \%)$ was also reported by Sasmaz et al. ${ }^{25}$

The reported IAT score in the present study was $52.1 \pm 16.3(20-90)$ which is conformed to the report of Dawood et al. $^{5}$, Ngai ${ }^{20}$ whereas A much lower score was reported by Kilic et al. ${ }^{23}$ The present study showed that the mean score of IAT was significantly higher among males. This is in concordance with other studies. $^{4,5,24}$ Several studies from different areas in the world reported that male gender is an independent risk factor for PIU. ${ }^{22,23,25,26,27}$

Moreover, Anderson et al. ${ }^{17}$ reported that the majority of the findings across different cultural samples support that males being at higher risk, and the difference between males and females regarding PIU is widening over time .

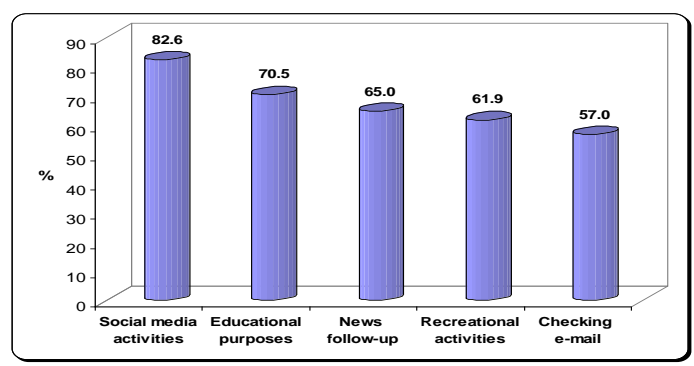

Fig. (2): Different internet uses through smartphones among adolescents

Different hypotheses and interacting factors were proposed to explain the differences revealed that males being targeted by the marketing strategies of higher PIU risk applications such as 
online games ${ }^{26,28}$ and also males in general are being at higher risk of developing addiction-related behaviors as PIU. ${ }^{29}$ On the other hand, Oktug ${ }^{30}$ reported that IA was higher among women than men.

As regards the different internet activities practiced, our study showed that activities on social media were significantly higher among males whereas using the internet for educational purposes was significantly higher among females. This is conformed to the finding of Çam \& İşbulan ${ }^{31}$ who reported that female students are less dependent on Facebook than male students.

Our study reported higher percent of bad interpersonal relation of adolescents who had PIU and/ or IA with their parents, family members and friends.

Bahrainian et al. ${ }^{32}$ reported that IA was associated with interpersonal factors such as perceived discontentment with peer interactions, few social friends and problems with parenting attitudes, family communication, family dissatisfaction, family cohesion and conflicting family relationships.

Moreover, an association was reported between greater internet use and a decline in participants' communication with family members in the household, a decline in the size of their social circle, and an increase in depression and loneliness. ${ }^{33}$ Weiser noted that excessive internet use negatively influenced psychological well-being by reducing social integration. ${ }^{34}$

It is probable that people become depressed and develop lonely as a result of being deprived from face-to-face interaction. It is unclear if depression or loneliness turns people avoiding human contact and drives them to interaction intervened by an electronic device. Likewise, it is possible that people with definite personality traits and preferences are driven to excessive use of the internet and the addiction results in enhancing the personality traits and preferences that causes a vicious cycle. ${ }^{35}$

PIU showed no significant difference related to the age of the participants. On the contrary, Vigna-Taglianti et al. ${ }^{24}$ reported significant higher prevalence among younger adolescents.

PIU was significantly higher among adolescents whom fathers were highly educated. This may reflect high income and socioeconomic state that facilitates easy access to the internet at home and having the recently updated generations of smartphones with more internet use options. The same finding was reported by Kilic et al. $^{23}$ as a significant risk for IA.

In the same context, the present study also reported that indoor availability of the internet was significantly associated with higher IA and PIU. Vigna-Taglianti et al. ${ }^{24}$ also reported that the majority of students accessed the internet from their home.

The years passed since first internet use didn't show significant effect on the internet use pattern in the present study. On the contrary, Nikhita et al. ${ }^{27}$ reported that internet use was significantly associated with increasing number of years of use.

In the present study, the highest uses of the internet were; social media activity, educational purposes, following news, recreational activities and e-mail messaging. The same activities were also reported by Tarimo \& Kavishe ${ }^{3}$ among secondary school students in Tanzania and $\mathrm{Ngai}^{20}$ among students in Hong Kong.

\section{Conclusion:}

The present study concluded that PIU through smartphones is prevalent among adolescents, males are more involved specially in social media activities. The PIU is significantly higher when internet access is available at home and among those whom fathers are highly educated. 
Bad family relation is significantly higher with PIU and IA.

Recommendations: Develop and expand awareness programs about the harmful consequences of internet use through interactive programs and mass media. parents could be suggested to supervise/restrict use of mobiles phones to only few hours per day among their children. Make use of non-smartphones and restrict the use to necessary ones in case of young users.

\section{References}

1. Helaleh Q, Qasim NC, Esmaili KA. Identity styles, loneliness and fear of intimacy among internet addicts and normal individuals. National studies 2015; 15:11736. Available from: http://www.sid.ir/En/Journal/ViewPaper.asp $\mathrm{x} ? \mathrm{ID}=465523$

2. Kwon M, Kim D-J, Cho H, Yang S. The Smartphone Addiction Scale: Development and Validation of a Short Version for Adolescents. Choi D-S, editor. PLoS One 2013;8(12):e83558. Available from: http://dx.plos.org/10.1371/journal.pone.0083 558

3. Tarimo R, Kavishe G. Internet access and usage by secondary school students in Morogoro Municipality, Tanzania. Int J Educ Dev using Inf Commun Technol 2017;13(2):56-69. Available from: http://ijedict.dec.uwi.edu/viewarticle.php?id $=2338$

4. Sahin C. An analysis of Internet addiction levels of indivuduals according to various variables. Turkish online J Educ Technol. 2011;10(4):60-6.

5. Dawood E, Mitsu R, Monica A. Patterns of Internet Use among Saudi Public Adults : A Cross Sectional Study. J Heal Med Nurs. 2015;13:18-28.

6. Turel O, Serenko A, Bontis N. Family and work-related consequences of addiction to organizational pervasive technologies. Inf Manag2011; 48(2-3):88-95. Available from: https://www.sciencedirect.com/science/articl e/abs/pii/S0378720611000176

7. American Psychiatric Association. Diagnostic and Statistical Manual of Mental Disorders, 5th Edition (DSM-5). Diagnostic Stat Man Ment Disord 4th Ed TR. 2013;280. 8. Lai C-M, Mak K-K, Watanabe H, Ang
RP, Pang JS, Ho RCM. Psychometric Properties of the Internet Addiction Test in Chinese Adolescents. J Pediatr Psychol [Internet]. 2013;38(7):794-807. Available from: http://www.ncbi.nlm.nih. gov/pubmed/23671059

9. Petersen KU, Weymann N, Schelb Y, Thiel R, Thomasius R. Pathological Internet use--epidemiology, diagnostics, co-occurring disorders and treatment. Fortschr Neurol Psychiatr 2009 ;77(5):263-71. Available from: http://www.ncbi.nlm.nih.gov /pubmed/19418384

10. Christakis DA, Moreno MM, Jelenchick L, Myaing MT, Zhou C. Problematic internet usage in US college students: a pilot study. BMC Med 2011; 9(1):77. Available from: http://bmcmedicine.biomedcentral.com/articl es/10.1186/1741-7015-9-77

11. Ahmadi K. Internet addiction among Iranian adolescents: A Nationwide Study. Acta Med Iran. 2014;52(6):467-72.

12. Grant JE, Potenza MN, Weinstein A, Gorelick DA. Introduction to Behavioral Addictions. Am J Drug Alcohol Abus 2010;36(5):233-41. Available from: https://www.ncbi.nlm.nih.gov/pmc/articles/P MC3164585/pdf/nihms319204.pdf

13. Billieux JJ. Problematic Use of the Mobile Phone: A Literature Review and a Pathways Model. Curr Psychiatry Rev 2012;8(4):1-9. Available from: http://www.eurekaselect.com/openurl/conten t.php?genre $=$ article $\&$ issn $=1573$ -

$4005 \&$ volume $=8 \&$ issue $=4 \&$ spage $=299$

14. Roberts J, Yaya L, Manolis C. The invisible addiction: Cell-phone activities and addiction among male and female college students. J Behav Addict 2014;3(4):254-65. Available from: http://www.akademiai .com/doi/abs/10.1556/JBA.3.2014.015

15. Boumosleh J, Jaalouk D. Smartphone Addiction among University Students and Its Relationship with Academic Performance. Glob J Health Sci 2017;10(1):48. Available from: http://www.ccsenet.org/journal/index.php/gj hs/article/view/71175

16. Mak K-K, Lai C-M, Watanabe H, Kim D-I, Bahar N, Ramos M, et al. Epidemiology of Internet Behaviors and Addiction Among Adolescents in Six Asian Countries. Cyberpsychology, Behav Soc Netw 2014;17(11):720-8. Available from: 
http://www.ncbi.nlm.nih.gov/pubmed/25405 785

17. Anderson EL, Steen E, Stavropoulos V. Internet use and Problematic Internet Use: a systematic review of longitudinal research trends in adolescence and emergent adulthood. Int $\mathbf{J}$ Adolesc Youth 2017;22(4):430-54. Available from: https://doi.org/10.1080/02673843.2016.1227 716

18. Young KS. how to recognize the signs of Internet addiction--and a winning strategy for recovery. J. Wiley; 1998. 248 p. Available from: https://www.wiley.com/eneg/Caught+in+the+Net:+How+to+Recognize +the+Signs+of+Internet+Addiction+and+a+ Winning+Strategy+for+Recovery-p9780471191599

19. Hawi NS. Arabic Validation of the Internet Addiction Test. Cyberpsychology, Behav Soc Netw 2013; 16(3):200-4. Available from: http://www.ncbi.nlm.nih.gov/pubmed/23441 685

20. Ngai SS. Exploring the Validity of the Internet Addiction Test for Students in Grades 5-9 in Hong Kong. Int J Adolesc Youth 2007; 13(3):221-37. Available from: http://www.tandfonline.com/doi/abs/10.1080 /02673843.2007.9747976

21. Goel D, Subramanyam A, Kamath R. A study on the prevalence of internet addiction and its association with psychopathology in Indian adolescents. Indian J Psychiatry 2013; 55(2):140-3. Available from: http://www.ncbi.nlm.nih .gov/pubmed/23825847

22. Mei S, Yau YHC, Chai J, Guo J, Potenza MN. Problematic Internet use, wellbeing, self-esteem and self-control: Data from a high-school survey in China. Addict Behav 2016; 61:74-9. Available from: http://www.ncbi.nlm.nih.gov/pubmed/27249 805

23. Kilic M, Avci D, Uzuncakmak T. Internet Addiction in High School Students in Turkey and Multivariate Analyses of the Underlying Factors. J Addict Nurs 2016; 27(1):39-46. Available from: http://www. ncbi.nlm.nih.gov/pubmed/26950841

24. Vigna-Taglianti F, Brambilla R, Priotto B, Angelino R, Cuomo GL, Diecidue R. Problematic internet use among high school students: Prevalence, associated factors and gender differences. Psychiatry
Res 2017; 257:163-71. Available from: http://dx.doi.org/10.1016/j.psychres.2017.07. 039

25. Sasmaz T, Oner S, Kurt AO, Yapici G, Yazici AE, Bugdayci R, et al. Prevalence and risk factors of Internet addiction in high school students. Eur J Public Health 2014; 24(1):15-20. Available from: http://www. ncbi.nlm.nih.gov/pubmed/23722862

26. Chang F-C, Chiu C-H, Miao N-F, Chen P-H, Lee C-M, Chiang J-T, et al. The relationship between parental mediation and Internet addiction among adolescents, and the association with cyberbullying and depression. Compr Psychiatry 2015; 57:218. Available from: http://www.ncbi .nlm.nih.gov/pubmed/25487108

27. Nikhita CS, Jadhav PR, Ajinkya SA. Prevalence of mobile phone dependence in secondary school adolescents. J Clin Diagnostic Res 2015; 9(11):VC06-VC09. Available from: http://www.ncbi.nlm. nih.gov/pubmed/26672469

28. Yang L, Sun L, Zhang Z, Sun Y, Wu $\mathrm{H}$, Ye D. Internet addiction, adolescent depression, and the mediating role of life events: Finding from a sample of Chinese adolescents. Int J Psychol 2014; 49(5):3427. Available from: http://doi.wiley.com/ 10.1002/ijop. 12063

29. Yu L, Shek DTL. Internet Addiction in Hong Kong Adolescents: A Three-Year Longitudinal Study. J Pediatr Adolesc Gynecol 2013; 26(3):S10-7. Available from: https://www.sciencedirect.com/science/articl e/pii/S1083318813001174

30. Oktuğ Z. Gender Differences in Internet Addiction and Tendency to Express Emotions. Available from: http://www.tojce. com/frontend/articles/pdf/v01i04/toctober5.p df

31. Çam E, İşbulan O. A new addiction for teacher candidates: social networks. 2012;11(3). Available from: https://files.eric. ed.gov/fulltext/EJ989195.pdf

32. Bahrainian SA, Alizadeh $\mathrm{KH}$, Raeisoon MR, Gorji OH, Khazaee A. Relationship of Internet addiction with selfesteem and depression in university students. J Prev Med Hyg 2014; 55(3):86-9. Available from: http://www.ncbi.nlm.nih.gov /pubmed/25902574

33. Kraut R, Patterson M, Lundmark V, Kiesler S, Mukophadhyay T, Scherlis W. Internet paradox: A social technology that 
reduces social involvement and psychological well-being? Am Psychol 1998; 53(9):1017-31. Available from: http://doi.apa.org/getdoi.cfm?doi=10.1037/0 003-066X.53.9.1017

34. Weiser EB. The Functions of Internet Use and Their Social and
Psychological Consequences. CyberPsychology Behav 2001; 4(6):723-43. Available from: http://www.ncbi. nlm.nih.gov/pubmed/11800180

35. Weinstein A, Lejoyeux M. Internet addiction or excessive internet use. Am J Drug Alcohol Abuse. 2010; 36(5):277-83. 